\title{
The Role of Social Media in Empowering the Involvement of Women in Information Technology: A Case Study of Al-Qalam and Umaru Musa Yar'adua Universities
}

\author{
Sanusi Abu Darma ${ }^{1}$, Farida Aliyu ${ }^{1} \&$ Shafi'u Abubakar Kurfi ${ }^{2}$ \\ ${ }^{1}$ Department of Computer Science, Al-qalam University, Katsina, Nigeria \\ ${ }^{2}$ Department of Accounting, Umaru Musa Yar'adua University, Katsina, Nigeria \\ Correspondence: Shafi'u Abubakar Kurfi, Department of Accounting, Umaru Musa Yar'adua University, Katsina, \\ Nigeria, E-mail: abubakarkurfishafiu@gmail.com
}

Received: November 20, $2017 \quad$ Accepted: November 25, 2017

Online Published: January 13, 2018

\begin{abstract}
The under-representation of the women in the field of Information Technology (IT) in Nigeria has been closely observed over the last decade. One of the facts is that social media have been widely and intensively used in Nigeria, which is an effective way to empower women in the IT sector. This study aimed to investigate the role of social media in empowering the involvement of women in information technology. In order to achieve the objectives of this study the current study conducted a survey amongst the female students of Al-Qalam and Umaru Musa Yar'adua Universities and tried to find out how the use of social media is contributing to the growth of women involvement in the IT sector. For this purpose, a sample of 200 female students was taken from these Universities via convenience sampling techniques. The quantitative method was used to collect data for this study. The findings in this study revealed that there was a significant relationship between women's awareness and the encouragement of women in the IT sector through the use of the social media. Besides, there was a significant relationship between the empowerment of women and the encouragement of women in the IT sector through the use of the social media. Hence, women's awareness and empowerment of women through the social media encouraged the involvement of women in the IT sector. In addition, this study recommends that there is need to examine the relationship between women and social media in various sectors such as government, healthcare, aerospace and security in order to trace the real role of social media in empowering the involvement of women in information technology in Nigeria.
\end{abstract}

Keywords: Social Media, IT, Women Empowerment, Women Encouragement.

\section{Introduction}

Information Technologies (IT) refers to the integration of telecommunication networks, computers, and audio-visual systems used to create access, store, transmit, and manipulate information (Bolanle, Zhang, Oluwadare \& Akintola, 2013). With such integration, it supports various applications in various fields like business, education, healthcare, and entertainment. Currently, it integrates also digital social media networks such as Facebook, Twitter, and YouTube (Ajjan, Beninger \& Crittenden, 2014). There are literally hundreds of different social media platforms (e.g bogging, micro-blogging, social networking, and text messaging, and shared photos), in which they have fundamentally changed the way individuals, communities, and organizations communicate and collaborate (Correa, Bachmann, Hinsley \& de Zúñiga, 2013). 
Currently, social media is referred to as a web-based service that allows individuals to construct a public or semi-public profile within a bounded system (Borrero, Yousafzai, Javed \& Page, 2014). Having been incorporated with various utilities, social media has infiltrated people's daily life with amazing rapidity to become an important social platform for computer-mediated communication ( $\mathrm{Lin} \& \mathrm{Lu}, 2011$ ). This is because they create, share, and/or exchange information and ideas in virtual communities and networks (Poonia, Scholar \& Bhurani, 2014) by providing a variety of new behaviors that were not previously possible, such as online collaborative authoring, online collaborative reviewing, online collaborative editing, online collaborative associating, and online collaborative experimenting.

The use of social media with its various tools has the potential to impact the lives of people in the developing world Nigeria inclusive (Wagner, Vollmar \& Wagner, 2014). In short, IT with the Internet in particular, has created a new era for social interaction. The Internet as a social space has provided various utilities for social interaction. Notably, there is a tremendous potential for using social media tool for the empowerment of Women worldwide (Ajjan et al., 2014). In education sector, females are seen less preferred to venture into the famously referred to science, technology, engineering, and mathematics (STEM) fields. They also have less interest in business sector (Moreno, González \& Segura, 2014). As a result, the trend shows gender imbalance in the participation of Women in the IT industry (Adya \& Kaiser, 2005). In fact, according to Crump, Logan and McIlroy (2007), most Women do not actively seek to be employed in IT. This should be overcome because the IT field should be ventured by the entire population in order to fulfill the need for skilled personnel (Wentling, 2009).

The phenomenon is just similar in Nigeria, in which the IT field is dominated by male personnel. Despite the lack of participation of Women in the field of IT, they tend to use social media for social interaction and relationship maintenance in the Internet. In contrast, males are more likely to spend their time online engaging in more task-focused activities such as reading news and retrieving financial information (Kimbrough, Guadagno, Muscanell \& Dill, 2013). That makes Women use social media more actively than men (Chen, 2013).

In addition, social media can provide ways for Women empowerment not limited to these following but including improve their income, improve their own and their families"e well-being, advance their children ${ }^{\text {ee }}$ education, and improve their status in their homes and communities (Hafkin, 2015). Nevertheless, social media can be a platform for Women to have discussion, sharing information and ideas on various matters. Social media also enabling them to educate themselves, let them gain awareness, exchanging opinions and participate effectively (Karolak \& Guta, 2015). Although the use of the Internet and social media in Nigeria is relatively low, it is gradually increasing since the last ten years (Abedalla, Escobar \& Al-Quraishi, 2014; Hashim, 2015). The users use them for various purposes. Although it is the fact that Women in Nigeria using social media more frequent than the men in high institution of learning, but the involvement of Women in Nigeria in IT is less than the men.

Therefore, the main aim of this study is to determine the impact of social media in empowering the involvement of Nigerian Women in IT. Other objectives of this study are:

- To determine the Women awareness for using social media in influencing them into the IT sector in Nigeria.

- To identify the role of social media in empowering Nigerians' Women to influence them into the IT sector.

\section{Literature Review}

The concept of Information Communication Technologies (ICTs) is an emerging field in the world of communication, which is wielding an unimaginable influence on global activities. It restructures 
politics/governance, economy, culture, health etc. in many countries and regions around the world (Sanda and Kurfi 2013). The ICT provides a great development opportunity by contributing to information dissemination, providing an array of communication capabilities, increasing access to technology and knowledge among others. Individuals and groups have accepted it globally as a tool for enhancing their varied interest. Tiamiyu (2003) opined that the ICTs are the electronic technologies for creating, acquiring, storing, processing, communication and using information. This involves the process whereby computers and other related machines are used in the dissemination and retrieval of information. While Cummings and O'Nell (2015) described that ICT is an umbrella term for the many devices that can be used to communicate information. These include older technologies, such as radio, television and video, and newer ones, such as computers, mobile phones (a type of computer) and the internet. The newer ones are new technologies from what is originally known in the traditional mass media of the print and broadcast. Wilson and Lawal (2015) pointed out that in contemporary Nigeria, the ICT has become a household name, used in offices and at home to access, receive and retrieve information. Emphasis is being placed in the use of the ICTs to access the world at large. Similarly, many innovations in the world today are as a result of the exposure and access to the world of the ICTs, and people all over the world can access any part of the world to receive information about whatever that borders their interests in life.

From the aforementioned explanations of prior studies, current study concludes that the concepts of Information and Communication Technology is a compendium of interrelated applications, products and services that helps humanity in its entirety. It has successfully transformed education, businesses, healthcare, entertainment, politics and good governance within the Global; providing equitable access to developmental framework driven by ICTs. In the Nigerian context, Information and Communication Technologies (ICTs) comprise a jcomplex, heterogeneous and interrelated set of goods, applications and services used to process, produce, distribute and transform information. Deferment

\subsection{Information Technology and Women in Nigeria}

ICTs have created new economic and social opportunities all over the world, and women have been able to use ICTs to support new forms of information exchange, organization and empowerment nowadays. In Nigeria, gender differences in ICT use is linked to patterns of discrimination in the society at large as well as with patterns of power relations within the home (Sanda and Kurfi 2013). According to Jensen (1997) only 10 percent of the people riding the information superhighway via the internet are women. In the same line of thought, Okunna (2000) opined that this is the twenty-first century, but yet tradition, culture, religion and other factors have continued to widen the disparity between Nigerian men and women at the expense of women. Furthermore, in many parts of the world, high female illiteracy rates mean that women have little access to the print media. As for television and radio, women may not always be able to watch or listen to their preferred programmes due to so many obstacles, including spending most of their times caring for children (Wilson and Lawan 2015).

In an entrenched patriarchal society like Nigeria, women were much less likely to use media especially computer based media. This is partly because women lack the necessary skills to make use of the ICTs and had many negative attitudes about these media. Notwithstanding, in recent years there are some changes in women's use of the ICTs whereby they are now developing skills needed to operate this new technology effectively. The potential of the ICTs for the advancement of women is considerable. Networking, study, training, sharing of ideas and information- all these could be infinitely easier through relatively affordable computer-mediated communications such as E-mail, Internet hypertext and hypermedia (Sanda and Kurfi, 2015).

\subsection{Challenges of ICTs use for Women in Nigeria}

As a result of Africa's numerous problems such as poverty, high level of illiteracy among others, it is the worst 
hit. Just as in many areas of development (e.g. agriculture, health, and education), women face enormous challenges in ICT for their own development. Ikyembe, (2012), Eze (2014), George and Barnabas (2015), Sanda and Kurfi, (2015) and Danjuma, Onimode and Onche, (2016) spelt out the following points as the major bottlenecks of ICTs use for women most particularly in Nigeria:

\subsubsection{Infrastructure}

The success for the utilization of any ICT rests in the availability of the infrastructure that is set up in the environment. ICT infrastructure in most developing countries and costs are exceedingly high. The little infrastructure available is even concentrated in the urban areas, and the bulk of women live in the rural areas. This tends to pose a huge gender gap in access to communication. It affects the majority of women, who in most African countries including Nigeria are poor and are living in rural areas. They lack access to these infrastructures in terms of access to computers, electricity, phone lines, computer hard and software, servers etc. The infrastructure deficit of the rural areas coincides with gender demographics -more women live in rural areas than men. Therefore, majority of the population in rural areas, women have a smaller chance than men to access new technologies. Therefore, Nigerian women need to have an enough and adequate infrastructures for them to have a chance and proper use and utilization of ICT. These infrastructures also need to be relatively cheap for women more especially this time of recession in Nigeria.

\subsubsection{Socio-Cultural and Economic Problems}

The African Gender Institute (2003) stated that in some societies there is disapproval of women's request to overnight browsing in a public cyber café especially married women. Although, there is recently a transformation in the access to internet through cell phones, it nevertheless has its own limitations including the lack of resources to constantly buy recharge cards and data for the phones; the power failure to charge the phones; and more role conflict with the women's expectations as wives, as mothers, and as workers or full-time housewives. In other words, women have problems of time given their multiple roles and heavy domestic responsibilities. Their leisure hours are few and the centres may not be open when women can visit them. To yield positive results therefore, every meaningful policy should therefore reflect women's moral, spiritual, and cultural values.

Traditional cultural attitudes in most societies discriminate against women, depriving them access to education and technology. Girls are encouraged to take any job or encouraged to get married rather than seek higher education. There is also the issue of gender bias in attitudes towards women studying or using information technology. Many people hold outmoded views that girls cannot think or work scientifically and that science is too mechanical and technical for girls, thus discouraging female students.

Phobia is also another obstacle in that most women have developed it for ICT especially considering the negative perception of the ICT tool as a tool for domination and oppression of NGOs to disabuse the minds of women on ICT as a negative tool.

Lack of financial resources can hinder women to participate fully in ICT community. This is because almost all communication facilities cost money and majority of women are afflicted by poverty. Poverty is rooted in gender imbalances, which are in turn rooted in gender inequality dynamics that stem from issues which cut across race, religion, status, culture and geographical location among others. Thus in comparison to men, women are worst hit as a result of their very limited involvement in economic activities in relation to their male counterparts. Okunna (2000) stressing on this maintains that the major cause of poverty among women especially in Nigeria is their low access to credit and income-earning opportunities, as well as marginalization from major economic activities. 


\subsubsection{Education and Skills}

Gender imbalances in education access still persist in most developing countries, despite the fact that education of women has been shown repeatedly to effect improvements in health and economic welfare. Education involves literacy, language, computer skills and information literacy. In each case, women in developing countries are less likely than men to have the requisite education and knowledge. According to the United Nations Report (2000), two-thirds of the world's 876 million illiterates are women who reside mostly in developing countries. Similarly, women are also less likely to know the international languages that dominate the web. Therefore, given their limited access to schooling, women especially those living in the rural areas, are also much less likely than men to have computer skills. This results to limited exposure and isolation of many women in developing countries particularly those in rural areas to have access to education and other skills, which will enhance the utilization of these infrastructures.

\subsection{Empirical Literature}

Generally, social media supports the creation and exchange of user-generated contents (Tufekci \& County, 2008). It has also been proven as a potential tool for mobilising attention and accountability to women's rights, and challenging discrimination and stereotypes (Nowacka \& Estelle, 2015). In fact, Chen (2013) found that women use social media especially blog more than men. However, in terms of variations, previous studies discovered that men use more tools than women, based on their needs. This includes searching for job and searching for dates, reading policies, accessing information about sports, playing games, reading news, and searching for financial information (Kimbrough et al., 2013). Besides, both men and women make use of social media tools to learn from others, and to strengthen social relations (Kimbrough et al., 2013).

Nevertheless, there are tremendous potentials for using social media platforms as a means for empowering women around world. As an example, social media tools like Twitter, Facebook, and Instagram play significant roles in their engagement in the Arab Spring, which supports political empowerment. This further strengthens their psychological empowerment (Newsom \& Lara, 2012).

In addition, Lehtonen (2014) found that the social media worked well as a general tool during the Arab uprising it also empowered the women activists at personal level, which functioned as an encouragement system among the women. Women were eager to participate in the uprising and in the politics of their country when social media offered a place for freedom of expression, increased awareness, and encouragement among women.

With such awareness, Zaidan et al. (2015) discovered that women in Palestine, Nigeria and other Middle East countries use social media tools to educate underserved women. They give a free health counselling using those tools besides organizing health education programs. Such initiatives are highly potential because adaptation into the tools is flexible and easy. With that, they could be used in approaching the society efficiently and effectively. Furthermore, Abisola, Oyesomi, Nelson and Omole in Nigeria (2014) found out that social media empowers and encourages women in diverse ways, one of which is that the social media encourages women to engage in economic activities that build-up networks with colleagues, business partners, workers, and clients.

Croasdell, McLeod \& Simkin (2011) have identified a number of reasons managers should attract females in the IT industry. The main one is that experienced and qualified IT professionals are scarce, causing many organizations to pay high salaries and offer sign-on bonuses, in order to attract top employees through change their ages. However, Croasdell et al. (2011) discovered that women do not choose to major in IT fields because they tend to focus on their family. The influence of family impacts the decision to choose an IT profession. These very same factors are important to the retention and recruitment of women in the IT profession.

Heinze \& Hu (2009) studied the factors that affected college undergraduates' choice to pursue a major in IT. The study found that attitudes toward IT affected the students toward IT majors. The study implied that negative 
stereotypes have a tendency to affect a student's attitude. As such, a socially withdrawn male does not encourage females to participate in the IT industry. The underrepresentation of 28 women in IT shows there may be truth in this perception. According to the studyer, the social aspect of the IT industry should be addressed with efforts to attract a broad range of IT professional.

According to Trauth et al. (2008), the collaboration of the less participation of women in the field of IT workforce and boost cultural variety is a result of the globalization of the IT field and is a problem in study and practice. Thus, there is a need for an investigation of the factors affecting in gender. In order to maximize the possible solutions focused to enhance social inclusion of women in the field of IT, The study of information technology needs to account for cultural contexts. In turn, analysed cultural factors that influenced women career choices in the IT profession.

Blum, Frieze, Hazzan \& Dias (2007) argued that women need a female friendly environment to share and be successful in IT. According to the authors, women can fit in any computing environment under certain environmental and cultural conditions. Culture is defined as a set of behaviours, values, relationships, attitudes and which are connected a specific community consciously and unconsciously. Environmental and cultural conditions attributed to the way women and men related to IT and are being moulded by those occupying it.

Blum et al. (2007) conducted three case studies. One particular case study studied undergraduates at Carnegie Mellon University in the Computer Science (CS) department. Before 1999, the CS department was imbalanced in the areas of gender, professional support for women students and student personalities. This department was geared toward male students. The women had an extremely low sense of self and felt they do not tend to get along well with the computing environment. In 1990 the new admission criteria allowed diversity in a balanced environment. The study found 29 that diversity and balance in the Carnegie Mellon University CS Department produced an environment where male and female students had similar attitudes toward IT. Some male and female students loved programming and some did not. The shift in the environment produced a change in the female students' confidence levels, perspective of programming and a sense of belonging.

Upon all of the above mentioned importance of social media in this contemporary world non from the aforementioned studies concentrates on the role of social media in empowering the involvement of women in information technology in Nigeria. Thus, in Nigeria too, there is dire need to carry out an empirical study to assess the impact of social media in the involvement of Nigerian women in IT.

\section{4 Study Framework}

The theoretical framework of this study focus on the use of communication technology, especially social media tools, in bringing awareness and empowerment to women more than ever before. Although not without its limits, electronic communication puts the women in touch with one another for sharing ideas and concerns (Heuwagen, 2014).

Accordingly, based on the conceptual model by Ajjan et al. (2014) (Figure 1), the theoretical framework for this study enables the exploration of the roles of social media in empowering and increasing the awareness for women in IT as illustrated below:

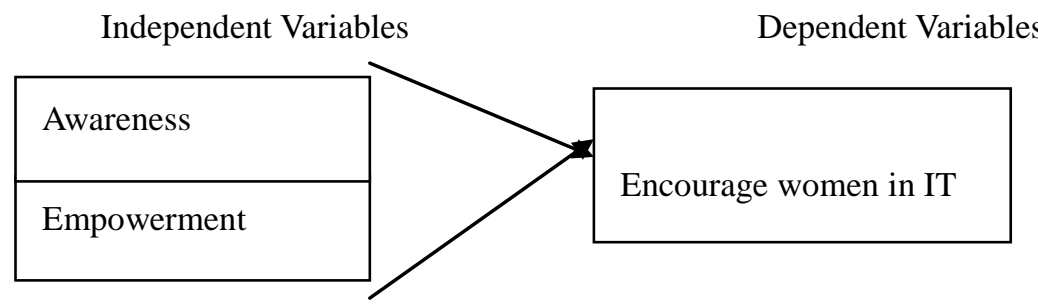

Figure: 1 
2.4.1 Women's Awareness and IT

Awareness is defined as an introduction to informed action, while awareness focuses on the knowledge on certain thing and how to positively impact the concern. This concept extends to public awareness, which helps individuals understand and drive other individuals to participate effectively in activities (Zita, Burger \& Scholtz, 2014).

On the other hand, online communities have recognized the social media as a highly effective tool for boosting the awareness and organizing movements on a wide range of issues. The views of women, whether on an individual or collective basis, have been observed to significantly influence the promotion of women's rights internationally. In their endeavour to achieve improved accountability and action in the context of gender equality, women's rights movements have greatly benefitted from developments in the social media. Now, the participation of women in social media outlets such as Twitter, Facebook, Instagram and Google+ for the purpose of elevating awareness, deliberating strategies or organizing campaigns related to gender equality, is on the rise. At the grassroots level, actions initiated by female-associated networks have led to alterations in regulations and customary practices in various countries including India, Kenya, and Nigeria. However, gender equality movements cannot afford to rest on their laurels just yet. There is still a long way to go in terms of elevating the involvement of civil society towards enhancing the participation of women in decision-making procedures (Shirky, 2011).

Now, modern technology and innovative developments in the social media significantly alters the lives of women especially those living in male-dominated societies. A case in point concerns the realities faced by Arabian women, who, without the Internet, would be deprived of the opportunity to put across their opinions on a global stage. The internet is also a means for them to acquire information that might otherwise be blocked by social and political impediments. As the social media offers an avenue for an individual to express himself/herself, it is especially attractive to the fairer sex who appears to be more inclined towards self-expression (Karolak \& Guta, 2015). In fact, the ability for the creator to share, concerns, and emotions with others, results in an improved psychological well-being (Ajjan et al., 2014).

\subsubsection{Women's Empowerment and IT}

Empowerment in the circumstance of women's rights refers to their capacity to make tactical life choices in an environment where they were previously deprived of this opportunity (Kabeer, 1999). Stavrositu and Sundar (2012) argued that the very act of making their self-expression in public can instill a sense of empowerment in the bloggers. Empowerment influences the option for women to (a) decide on issues affecting them directly, (b) gain from resources and opportunities, (c) have power over the management of their own lives and bodies and (d) have a say in communal decisions which can potentially lead to a raised level of independence and improved well-being (Schuler \& Rottach, 2010).

They are meaningful, based on the definition by Keller and Mbewe (1991), that the empowerment of women is a procedure that facilitates their systemized endeavour to enhance their independence, exercise their autonomous right to make decisions, and manage resources that will help them to confront and do away with their own subordination. Kabeer (2001) cites the importance of empowering women through fostering their ability to challenge their contexts and make strategic choices in an environment where such choices were previously denied. Thus, increased access to information through social media can improve a woman se capacity to envision alternative options to make meaningful choices (Alsop \& Heinsohn, 2005).

\section{Methodology}

The current study aimed to study 'The Role of Social Media in Empowering the Involvement of Women in Information Technology: (A Case Study of Al-Qalam and Umaru Musa Yar'adua Universities)'. The survey was also used because it is a means of obtaining data which can be used to quantifying attitude, opinion, behaviours 
and other defined variables; as well as generalize result from a large sample population (Coleman, Haffer and Kilgore, 1987).

A questionnaire survey was used in this study as a measurement tool or data collection method to investigate The Role of Social Media in Empowering the Involvement of Women in Information Technology. The survey takes the form of hand delivery and it was administered by the studyers at Al-Qalam and Umaru Musa Yar'adua Universities. In this survey, the studyers had distributed the questionnaires to the targeted respondents who were willing to complete the questionnaires and return it to the studyer. This system was used because it gives the benefit of a degree of personal contact between the studyer and the respondents (Oppenhein, 1992). This encourages the respondents to complete the questionnaires and return them back to the studyer. Additionally, the technique was used because it is cost-effective and quicker to administer (Bryman\&Bell, 2003).

\subsection{Sampling Frame}

Population refers to the group of individuals, entities or anything that has one or more characteristics in common that are of interest (Creswell, 2008). They are 2106 female students in Al-qalam and 2779 female students in Umaru Musa Yar'adua University respectively making 4885 as total population of this study. Table 3.1 consist the list of the population of the study.

Table1.Population of the Study

\begin{tabular}{ll}
\hline University & Sub-total \\
\hline Al-Qalam University & 2106 \\
\hline Umaru Musa Yar'adua University & 2779 \\
\hline Total Population & 4885 \\
\hline
\end{tabular}

Sources: MIS units of the Universities as at $3^{\text {rd }}$ July, 2017

The population for this study was a sample population selected from Al-Qalam and Umaru Musa Yar'adua Universities. The Universities was chosen because of familiarity, close proximity and accessibility. This is in line with the study of Bryman and Bell (2003). Al-Qalam and Umaru Musa Yar'adua Universities are the only two universities in Katsina metropolis and in terms of women students' population the total was 4885 as at 3rd July, 2017.

\subsubsection{Sample Size}

In any study availability of data is important as such, this study tends to reduce the population size in order to have authentic and accurate results that can be generalize. The total number of female undergraduate students from the two Universities are 4696, then 176 for masters students and finally 13 students doing Phd programme from Umaru Musa Yar'adua University while none from Alqalam University as shown in Table 3.1. Having identified the population, they were sampled, as suggested by Stoker (1981) and Chasib (2014), so that this study could limit the process systematically. The stuy gained access to the sample population at the two Universities by issuing a structured questionnaire to the targeted respondent.

\subsubsection{Sampling Method}

The sampling method used was non-probability sampling (Convenience sampling). This sampling method involves respondents who were accessible, willing to take part in the study (Cress well, 2009). Non-probability sampling is a sampling that has not been selected using a random selection method (Brynman, \& Bell, 2003). However, this type of sampling was acceptable and was used in this stuy because it was cost effective, and easier to access the targeted population (Moon, 2011). Thus, the sample size of this study is 200, and therefore 200 
questionnaires were issued while only 150 questionnaires were successfully returned.

The questionnaire comprised of 24 questions. The respondents were asked to complete closed-ended questions and the questionnaire was organized into four parts. Parts 1, 2, 3 and 4 as presented below:

Part1. Demographic Information:

This section deals with respondents personal information and profiles via structured questionnaire, the information was used to establish the potential credibility of data. In this section nominal \& ratio scales were used as measuring scales. The nominal data is a set of information organized by category or name. They are often used to describe respondents' personal information (Robson, 2011). Some of the nominal data used were Age, Level of Education, Social Media Usage and Social Media Login.

Part2.The Core Items on Women's Awareness of Using Social Media:

In this section five-point likert scale was used to quantify Women's Awareness of Using Social Media. Five-point likert scale is one of the most useful psychometric scaling for establishing attitudinal and behavioural measures (Carmine \& Irvine, 1988). Consequently, five-point likert scale was used as the evidence suggests that more complex scoring system possess no substantial advantage (Oppenheim, 1992). The five-point likert scale used are strongly agree, agree, neutral, disagree and strongly disagree. These are ordinal scale. The ordinal scale was used to describe the students' characteristic, attitudes and behaviours toward their usage of social network sites.

Part3. Women's Empowerment through Social Media:

The information obtained in this section was gathered through ordinal and nominal scale of measurement (qualitative measurement scales) (Kumar, 2005). Using five point likert scales (attitudinal scale) as stated above in section B. This scale was used based on the assumption that each item on the scale has equal value (Kumar, 2005).

\section{Part4. Encouraging the Involvement of Women in It}

The information obtained in this section was gathered through ordinal and nominal scale of measurement (qualitative measurement scales) (Kumar, 2005). Using five point likert scales (attitudinal scale) as stated above in section B. This scale was used based on the assumption that each item on the scale has equal value (Kumar, 2005).

\subsubsection{Methods of Data Analysis}

Descriptive analysis describes all variables in the study. In order to provide an in-depth Understanding of the relationship among the independent and the dependent variables of the study, a descriptive statistical analysis was conducted. According to Bryman \& Cramer (2011), a descriptive statistical analysis is used to explain the construct of the items in the questionnaire, where it is used to portray, show and clarify the information provided by specific respondents.

Statistics such as mean, standard deviation will be used in this study. These scales highlight the respondents' answer obtained from the data collected. These scales were then arranged to the classifications to show their level from answers towards all variables: 1.00 to 2.33 that is low level of mean, the moderate level of mean between 2.34 to 3.66 and the level from 3.67 to 5.00 is high (Mawaddah, 2013). They provide simple summaries about the sample and measurement (Trachim, 2009). Cronbach' Alpha was also used to test the internal consistency of the study data (Gliem and Gliem, 2003).

According to Murply and Briens et al, (2001) measuring the internal consistency of the data allows the study to generalized the result over the entire population. The data collected in this study include interval data for the ages, Nominal data for gender, residence, nature of study, and year of study, and the ordinal data for core items on social network sites and mobile technologies usage among the students (Allen, 2008). The ordinal data were in form of five points Linkert scal (Kumar, 2005). The five points likert scales includes (1) Strongly disagree (2) 
Disagree (3) Neutral (4) Agree and (5) strongly agree. After collecting the required data, the current study will used statistical software Stata Version 14 in order to process and develop evidence patterns related to the framework of this study. The study used this software due to its simplicity and user friendly criteria and it is suitable to analyse the type of data collected for this study. This is in line with the study of Chasib, (2014) and Charles. et al. (2014).

4. Result and Analysis

4.1 Demographic Analysis

Table 1 Background of the Respondent

\begin{tabular}{lccccc}
\hline Variables & Obs. & Mean & Std. Dev. & Min & Max \\
\hline Age & 131 & 2.5267 & 1.0328 & 1.0000 & 5.0000 \\
Edu.Qual. & 131 & 1.4503 & 0.7360 & 1.0000 & 3.0000 \\
SMU & 131 & 2.7939 & 1.2448 & 1.0000 & 6.0000 \\
SML & 131 & 1.6031 & 0.9741 & 1.0000 & 5.0000 \\
\hline
\end{tabular}

Source: Computation using STATA 14.0

Table1 Present the background of the respondent, age has an average score of 2.5267 and minimum score of 1.000 , and this implies that the average age of the respondents is within the age bracket of 23 to 25 years and below 18 years as the minimum age of our respondent. The maximum age is 45 years. Standard deviation of 1.0328 signified insignificant variation among the respondent in terms of age. The average educational qualification of the respondent is the first degree, with $\mathrm{PhD}$ as the maximum educational qualification. Standard deviation of 0.7360 signified significant variation among the respondent in terms of educational qualification Social media usage among respondent has a mean score of 2.7939 which suggest that, on average the respondents used whatsup to access social media while few of them used facebooks. The standard deviation of 1.2448 implied insignificant differences in the usage of social media applications among the respondents. The social media login has a minimum score of 1.6031 and a minimum value of 1.000 with maximum of 5 , this suggests that on average the respondent login their social media application once a day, only few number of them loge several times a day. The standard deviation of 0.9741 shows minimum variation among respondent in terms login to their social media account.

4.2 Reliability and Validity Test

Table 2 Reliability and Validity Test

\begin{tabular}{lcc}
\hline Questions & Percentage & Cronbach's Alpha \\
\hline Women's Awareness of Using Social Media & $38 \%$ & 0.55 \\
Women's Empowerment through Social Media & $46 \%$ & 0.67 \\
Encouraging the involvement of women in IT & $16 \%$ & 0.61 \\
\hline
\end{tabular}

Source: Computation using STATA 14.0

Table 2 present reliability and validity of our instruments which is necessary in any survey study so as to obtained robust results. Cronbach's alpha score is used using stata to test the validity and reliability of our instruments. The criteria are to accepts an alpha with minimum score of 0.50 and above while any question with alpha less than 0.50 is to be rejected (Garko, 2016). The instrument related to women awareness on using social media which accounts $38 \%$ of total questions has an average alpha of 0.55 which fall within the acceptance region. Similarly, the role of social media in women empowerment shows a mean alpha of 0.67 which suggest that our instruments to test women empowerment through social media are valid and reliable. Finally, 
encouraging the involvement of women in IT has an alpha score of 0.61 which indicates its validity and reliability.

4.3 Ordered Logit Regression

Table 3 Ordered logit Regression results (Dependent Variable- IT)

\begin{tabular}{|c|c|c|c|}
\hline Variables & Coefficient & $\mathbf{z}$ & $\mathbf{P} / \mathbf{z} /$ \\
\hline Women Awareness & 0.7815 & 2.83 & 0.005 \\
\hline \multirow[t]{4}{*}{ Women Empowerment } & 0.1980 & 1.79 & 0.073 \\
\hline & 12.06 & & \\
\hline & Pro> chi2 0.0024 & & \\
\hline & Pseudo $R^{2} 0.0370$ & & \\
\hline
\end{tabular}

Source: Computation using STATA 14.0

In order to examine the influence of social media in empowering the involvement of women in information technology, ordered logit regression were employed regarding the nature of questionnaire which is five liket scales. The Pseudo $\mathrm{R}^{2} 0.0370$ shows the extent to which women awareness and empowerment explains involvement of women in information technology, LR 12.06 and P-Value of 0.0024 shows the fitness of the model at $5 \%$ level of significance

The influence of women's awareness of using social media on women involvement in information technology is positive and likely significant at 5\% level of significant, this suggest that social media influence women awareness through information technology. Women's Empowerment through Social Media has positive and likely to be significant at $10 \%$ level of significant this suggest that women get empowered using social media.

\section{Summary, Conclusion and Recommendations}

\subsection{Summary}

The study examines the role of social media in empowering the involvement of women in information technology: (A Case Study of Al-Qalam and Umaru Musa Yar'adua Universities). The study used the survey method for acquiring the required data via distributing a questionnaire to targeted respondents. Stata version 14 has being used to find out the answers of the study. In order to examine the influence of social media in empowering the involvement of women in information technology, ordered logit regression were employed regarding the nature of questionnaire which is five liket scales.

\subsection{OBJECTIVE 1: To determine the Women awareness for using social media in influencing them into the IT sector in Nigeria}

For the first objective of this study, the respondents were provided with information related to their awareness of using social media that influences them into the IT sector in Nigeria. From the data analysis, it was found that majority of the respondents agree that they have the necessary awareness in using social media such as; Facebook, Whatsup Twitter, and YouTube as a contributing element that influences them into the involvement of women in IT in Nigeria. Thus, the result reveals that there is positive and significant impact of social media in empowering the involvement of women in information technology at 5\% level of significant, this suggest that social media influence women awareness through information technology.

Also, the results of analysis reveal that majority of the women are logging into and using social media, this suggests that on average the respondent login their social media application once a day only few number of them loged several times a day, which indicates that the awareness among women in Nigeria on the importance of the social media in their daily activities is relatively high. Besides that, this study examines on how Nigerian women use social media that influence them in the involvement of in IT including desire to share knowledge with others through the social media, downloading and uploading files, online discussion, share photos, videos and opinions, 
contact friends who are away, create and participate in group discussions, send messages, see comments and enhance awareness and sense of achievement.

Social media often provide topics of conversation for discussion and thus help to lubricate social life also it provide the possibility of keeping in touch with people nearby as well as women use the social media for entertainment and communication. These activities generate self-expression. Hence, women express themselves as well as gaining knowledge which influences in increase participation in IT workforce. This means that the social media is a platform for the women to discuss and share information and ideas on various matters, thereby educate themselves, exchanging opinions and importance of the effective participation.

In addition, the findings also show that the social media provides a strategy for sharing their opinions, raising awareness, and promoting participation in the field of IT sector in Nigeria. Participations in this study confirmed that they are aware of the benefits of social media that encourage women in the involvement of IT. Based on the discussions in this paragraph and the previous, the study objective one has been achieved.

These findings of this study are in consistence with the findings of Lehtonen (2014) that showed that social media provides a strategy for sharing their opinions, raising awareness, and promoting participation. Besides that, women are effectively using social media as a tool for raising awareness among their social networks. Also, social media functions as a platform for opinion expression and enables sustaining interest among networks. Nevertheless, the importance of sharing information and raising awareness in the community results from efficiency, and those women strategically share thoughts everywhere they want; thus, this shows the utilization of both strong and weak ties in their networks.

\subsection{OBJECTIVE 2: To identify the role of social media in empowering Nigerians' Women to influence them into the IT sector.}

For the second objective, the respondents were provided with information related to social media empowerment and its roles on encouraging women to join the IT sector in Nigeria. From the data analysis, the results show that there are significant relationship between empowerment and IT sector. The respondents believe that social media helps women to understand the challenges such as social and structural factors as illustrated in the literatures and enable them on it. From the analysis, Women's Empowerment through Social Media has positive and likely to be significant at $10 \%$ level of significant this suggest that women get empowered using social media.

It was found that majority of the respondents agree that the social media provides them a platform to speak out about their lives, needs, and issues that they face as well as social media provides them with opportunities to bring information on every issues to them at their doorstep, and reach everyone in new ways. Many also agree that social media allows them to do things that many of them could otherwise never do, and it encourages them to improve the standard of living as well as develop their ideas and creativity.

In association with self-confidence and social interactions, the results indicate that women in Nigeria have moved forward towards a higher level of self-confidence and have increased their social interactions due to the use of social media. Many respondents indicate that the use of social media helps them in maintaining good relationships among each other through online interactions. The advancement of social media in Nigeria has also helped the women feel that they are significant in the society, increased self-reliance, more independent, and increased their participation in decision-making on domestic issues besides making them feel confident to be able to work along with their male colleagues.

Social media also serves as a gateway to benefits around empowerment denoting a variety of ideas, including self-confidence, autonomy, and the capacity to alter the structures that govern one's situation. Empowerment benefits flow from the fact that the social media permits information, ideas and perspectives to travel with greater ease. With that, it allows women to enlarge and develop their communities. Nevertheless, social media 
helps the Nigerians' women to understand the barriers they face in participating in the field of IT, such as structural and social factors.

The discussions in this paragraph and the previous show that the participations agree that social media is a tool for empowering the women to involve in IT sector in Nigeria. Thus, the study objective two has been achieved. These findings of this study are in line with the findings of Beena and Vidyapith (2012); Khan and Moin (2013) that vividly revealed that the IT especially social media empowers a women in various areas like social, educational, personal, psychological, political, and economical. In addition, Abisola, Oyesomi, Nelson and Omole (2014) found out that social media empowers and encourages women in diverse ways, one of which is that the social media encourages women to engage in economic activities that build-up networks with colleagues, business partners, workers, and clients. This study concludes that women make use of the social media as a veritable source of empowerment in different spheres of life.

\subsection{Conclusion}

This study was conducted with the aim of identifying the role of social media in empowering the involvement of women in information technology: (Study Of Al-Qalam And Umaru Musa Yar'adua Universities). The study also designed a framework to shows how the social media empower the involvement of women in IT a. This study uses quantitative data analysis techniques based on the questionnaire distributed to female students' Al-Qalam and Umaru Musa Yar'adua Universities.

The descriptive analysis provides reliable evidences that support the respondents' high level of agreements towards the use of social media and its influences, where the independent variables; Awareness and Empowerment; are found to be correlated with the dependent variable; Encouragement. Thus, according to the data analysis conducted and described in Chapter 4, it can be concluded that there is a high level of awareness and empowerment among women in Nigeria regarding the role of social media and its influences in encouraging them to involve in the IT sector.

As a conclusion, it is found that although social media is presumably new in Nigeria because it is not more than one decade now, it has started contributing towards the indication of success and advancement amongst the Nigerians' women. This is perhaps due to the fact that as a developing country, Nigeria is ready to accept any new innovation that will help them to compete with other countries of the world. Additionally, the emergence of the technology era has taken its effect and has been accepted into the general norm of live and into the general aspect of lives of women.

\subsection{Recommendation for Future Studies}

In the light of the analysis and findings and conclusions the following recommendations are made which would improve the involvement of women in IT sector in Nigeria by using social media:

i. More study in the area of awareness of the use of social media within the general aspect in IT is required, in order to enhance the understanding on the influence of social media towards employment in general, and towards employment of women into specific sectors like entrepreneur etc.

ii. Studies have shown that women participate less in the IT profession (Neuhauser, 2007; Panko, 2008; Wentling, 2009). Thus, in order to understand the under-representation that goes deeper than a quantitative study, future study could be done using a qualitative methodology due to the time limit and resources.

iii. Another recommendation for future study is to examine the relationship between women and social media in various sectors such as government, healthcare, aerospace, and security. 
References

Abedalla, R. W., Escobar, L. S. \& Al-Quraishi, D. A. (2014). Accessing Information Technology- Social Media in Nigeria. Scientific and Research Publications, 4(9),1-6

Abisola, S., Oyesomi, K., Nelson, O. \& Omole, F. (2014). How Sociable are Women on Social Media? An Experiential Study on Nigerian Women. International Journal of Research in Social Sciences, 4(2), $57-72$.

Adya, M. \& Kaiser, K. M. (2005). Early Determinants of Women in the IT Workforce: A Model of Girls ${ }^{e e}$ Career $^{\circ}$ Choices. Information Technology \&People, 18(3), 230-259.

Ahuja, M. K. (2002). Women in the Information Technology Profession: A Literature Review, Synthesis and Research Agenda. European Journal of Information Systems, 11(1), 20-34.

Ajjan, H., Beninger, S. \& Crittenden, V. L. (2014). Empowering Women Entrepreneurs in Emerging Economies: A Conceptual Model. Organizations And Markets In Emerging Economies, 5(1), 16-31.

Ali, F. A. \& Aliyu, U. Y. (2015). The Use of Social Networking among Senior Secondaryn School Students in Abuja Municipal Area of Federal Capital Territory, Nigeria. Journal of Education and Practice, 6(15), $15-23$.

Al-mukhaini, E. M. (2014). Adoption Of Social Networking In Education: A Study of The Use of Social Networks by Higher Education Students in Oman.Journal of International Education Research, 10(2), $143-154$.

Al-Rawi, A. K. (2014). The Arab Spring \& Online Protests in Nigeria. International Journal of Communication, 8 , 916-942.

Alsop, R. \& Heinsohn, N. (2005). Measuring Empowerment in Practice: Structuring Analysis and Paper Framing Indicators. World Bank Policy Research Working, 5(2), 123.

Amanda, W. \& Michael, M. (2009). Adolescents ${ }^{e e}$ Online Social the Death of a Peer. Journal of Adolescent Research, 24(1), 67-90

Angela, N. (2013). Not Quite Kicking Off Everywhere: Feminist Notes on Digital Liberation. Internet Research, 9, 157-175.

Anne, M. (1993). Chasing Shadows: Alienation in Working Women. Equal Opportunities International, 12, 20-22.

Appelrouth, S. \& Edles, L. D. (2010). Sociological Theory in the Contemporary era: Text and Readings. Pine Forge Press.

Armstrong, D., Nelms, J., Riemenschneider, C. \& Reid, M. (2012). Revisiting The Barriers Facing Women In Information Systems. Journal of Computer Information Systems,53(2).

Armstrong, D. \& Riemenschneider, C. (2014). The Barriers Facing Women in the Information Technology Profession: An Exploratory Investigation of Ahujaes Model. ACM, 5(29), 85-96.

Ary, D., Jacobs, L. C., Razavieh, A. \& Sorensen, C. (2009). Introduction to Research in Education. Getting Started in PER, 12(3), 669.

Balcita, A. M., Carver, D. L. \& Soffa, M. L. (2002). Shortchanging The Future of Information Technology: The Untapped Resource. SIGCSE Bulletin, 34(2), 32-35.

Barker, V. (2009). Older Adolescents ${ }^{e e}$ Motivations for Social Network Site Use : The Influence of Gender, Group Identity, and Collective Self-Esteem. ResearchGate, 12(2), 209-213.

Barrett, M. \& McIntosh, M. (2005). Ethnocentrism and Socialist-Feminist Theory. JSTOR, 80(20), 64-86. 
Baruch, R. (2014). Women and Information Technology: How Do Female Students of Education Perceive Information Technology, and What is Their Approach toward It ? Journal of International Women's Studies, 15(1), 190-214.

Beasley, C. \& Bacchi, C. (2007). Envisaging a New Politics for an Ethical Future: Beyond Trust, Care and Generosity towards an Ethic of 'Social Flesh'. SAGE, 8(3), 279-298.

Beddoes, K. \& Borrego, M. (2011). Feminist Theory in Three Engineering Education Journals: 1995-2008. Journal of Engineering Education, 100(2), 281-303.83

Beena, M. \& Vidyapith, B. (2012). Role of ICT Education for Women Empowerment. International Journal of Economic Research, 3(3), 164-172.

Berson, I. R. (2003). Grooming Cybervictims The Psychosocial Effects of Online Exploitation for Youth. Journal of School Violence, 2(1), 5-18.

Bimrose, J., Watson, M., McMahon, M., Haasler, S., Tomassini, M. \& Suzanne, P. (2014). The Problem with Women? Challenges Posed by Gender for Career Guidance Practice. International Journal for Educational and Vocational Guidance, 14, 77-88.

Blanchard, M., Herrman, H. \& Burns, J. (2008). Study of Marginalised Young People " s Findings From A study of Marginalised. ResearchGate, 27(4), 35-42.

Blum, L., Frieze, C., Hazzan, O. \& Dias, M. B. (2007). A Cultural Perspective on Gender Diversity in Computing. Special Interest Group on Computer Science Education, 12(5), 4-20.

Boase, J., Horrigan, J. \& Wellman, B. (2006). The Strength of Internet Ties. Pew Internet \& American Life Project, 25(1), 1-65.

Bolanle, O., Zhang, M., Oluwadare, S. \& Akintola, K. (2013). Women "es Perceptions and Uses of Information and Communication Technologies in Nigeria and China : A Comparative Analysis. Information Management and Business Review, 5(4), 203-216.

Borrero, J. D., Yousafzai, S. Y., Javed, U. \& Page, K. L. (2014). Expressive Participation in Internet Social Movements: Testing the Moderating Effect of Technology Readiness and Sex on Student SNS Use. Computers in Human Behavior, 30, 39-49.

Boyd, D. M. \& Ellison, N. B. (2007). Social Network Sites: Definition, History, and Scholarship.Journal of Computer-Mediated Communication, 13(1), 210-230.

Broos, A. (2005). Gender and Information and Communication Technologies (ICT) Anxiety: Male Self-assurance and Female Hesitation. CyberPsychology \& Behavior, 8(1), 21-31.

Bruns, A. (2008). Blogs, Wikipedia, Second Life, and Beyond: From Production to Produsage.Peter Lang.

Bryant, E. M. \& Marmo, J. (2011). A Functional Approach to Social Networking Sites.Computer-Mediated Communication in Personal Relationships, 22(10), 3-20.

Bryman, A. \& Cramer, D. (2011). Quantitative Data Analysis with IBM SPSS 17, 18 and 19: A Guide for Social Scientists. Routledge.

Buchanan, D. \& Bryman, A. (2007). Contextualizing Methods Choice in Organizational Research. Organizational Research Methods, 10, 483-501

Burch, S. \& Leon, I. (2000). Networking for Change Women in Sync The APCWNSPs First 8 Years. APC, $12(1), 100$.

Burgess, J., Foth, M. \& Klaebe, H. (2006). Everyday Creativity As Civic Engagement: A cultural Citizenship View of New Media. Proceedings Communications Policy \& Research Forum, 9(26), 1-15. 
Cattane, V. (2012). Egyptian Women Bloggers: Perceptions of Empowerment in the Online Public Sphere. Journalism and Mass Communication Department, 0752, 105.

Charles, O., Helen, N. \& Jennifer, N. (2014). The Use of Social Networking Sites among the Undergraduate Students of University of Nigeria, Nsukka. Library Philosophy and Practice, 5(3), 56-66.

Chasib, H. A. (2014). Exploring the Effect of Cuber-bullying on Student Attitude in Online Learning: A Case Study of UUM. UUM.

Chen, G. M. (2012). Why do Women Write Personal Blogs? Satisfying Needs for Self- 171-disclosure and Affiliation Tell Part of the Story. Computers in Human Behavior, 28(11), 180.

Chen, G. M. (2013). Why do Women Bloggers Use Social Media? Recreation and Information Motivations Outweigh Engagement Motivations. New Media \& Society, 1-17.

Chou, Y., Yen, H. \& Sun, C. (2014). An Integrate Method for Performance of Women in Science and Technology based on Entropy Measure for Objective Weighting. Springer, 8(8), 4-16.

ClummingC.O'TeilN.,(mar2015).Dodigital information and commucationtechnologyincrease The voice and influence women and girl.

Coleman, S. \& Rowe, C. (2005). Remixing citizenship. Democracy and Young People Use of the Internet, 7(15), 33.

Collin, P., Rahilly, K., Richardson, I. \& Third, A. (2011). The Benefits of Social Networking Services. Research Report, 10(22), 4-29.

Correa, T., Bachmann, I., Hinsley, A. \& de Zúñiga, H. (2013). Personality and Social Media Use.IGI Global.

Creswell, J. W. (2003). Research design Qualitative Quantitative and Mixed Methods Approaches. SAGE.

Creswell, J. W. (2008). Editorial: Mapping the Field of Mixed Methods Research. Journal of Mixed Methods Research, 3(2), 95-108.

Croasdell, D., McLeod, A. \& Simkin, M. G. (2011). Why Don"t More Women Major in Information Systems? Information Technology \& People, 24, 158-183.

Crump, B. J., Logan, K. \& McIlroy, A. (2007). Does Gender Still Matter? A Study of the Views of Women in the ICT Industry in New Zealand. Gender, Work and Organization, 14(4), 349-370.

CSO Nigeria. (2012). University and Technical Education Report. Central Statistical Organization (Vol. 5).

Chou, Y., Yen, H. \& Sun, C. (2014). An Integrate Method for Performance of Women in Science and Technology based on Entropy Measure for Objective Weighting. Springer, 8(8), 4-16.

Correa, T., Bachmann, I., Hinsley, A. \& de Zúñiga, H. (2013). Personality and Social Media Use. IGI Global.

Crump, B. J., Logan, K. \& McIlroy, A. (2007). Does Gender Still Matter? A Study of the Views of Women in the ICT Industry in New Zealand. Gender, Work and Organization, 14(4), 349-370.

Dale, C., Xu, C. \& Jiangshuan, L. (2008). Statistics and Social Network of YouTube Videos.IEEE, 15(6), 229-238.

Danjuma,K. J., Onimode, B. M., \& Onche, O. J.(2015). Gender Issues \& Information Communication Technology for Development (ICT4D): Prospects and Challenge for Women in Nigeria.

Das, S. K. \& Bhowal, A. (2013). Self Help Groups as an Empowerment Model: Perceptions of Direct Stakeholders. American Journal of Rural Development, 1(5), 121-130.

Den Broeck, J. \& Fadnes, L. T. (2013). Data Cleaning. In Epidemiology: Principles and Practical Guidelines (pp. 389-399). Springer.

Donna, H. (1988). Situated Knowledges: The Science Question in Feminism and The Privilege of Partial Perspective. JSTOR, 14(3), 575-599. 
Donovan, J. (2012). Feminist Theory: The Intellectual Traditions. Bloomsbury Publishing USA.Duehr, E. E. \& Bono, J. E. (2006). Men, Women, and Managers: Are Stereotypes Finally Changing? Personnel Psychology, 59, 815-846.

Dubai School of Government, (Nov 2011). The Role of Social Media in Arab Women's Empowerment. Arab Social Media Report, 1(3).

Edosomwan, S. (2011). The History of Social Media and its Impact on Business. Applied Management and Entrepreneurship, 16(3), 1-13.

Enns, C. Z. (1992). Toward Integrating Feminist Psychotherapy and Feminist Philosophy.Professional Psychology: Research and Practice, 23(6), 453.

Eze, D.(4,Aug,2014). Nigeria And The Crisis Of Culture Identity In The Era Of Globalization.journal of Africa studies and development, 6(8), 140-147.

Friborg, O. \& Rosenvinge, J. H. (2013). A comparison of Open-ended and Closed Questions in the Prediction of Mental Health. Springer Science Business Media, 47(24), 1397-1411.

Gajjala, R. (1999). Cyberfeminism, Technology and International Development. Gender \& Development, 7(2), $8-16$.

Gayles, J. G. (2014). Attracting and Retaining Women in STEM. IEEE, 10(14), 90-93.

Gazzar, N. El. (2011). Adolescentse Perception and Attitudes Towards Social Media Netowrks in Egypt - A Survey. In In Proceedings of the EU Kids online Conference (Vol. 21, pp. 1-23).

George, T. O., and Barnabas Suleiman. (2015). ICT and the Gender Question: Prospects and Challenges for the Knowledge Economy in the 21st Century. International Conference on African Development Issues (CU-ICADI) 2015 : Social and Economic Models for Development Track.

Giesen, D., Meertens, V., Visschers, R. \& Beukenhorst, D. (2012). Questionnaire Development. Statistics Netherlands, (12), 1-82.

Giles, G. \& Price, I. R. (2008). Adolescent Computer Use: Approach, Avoidance, and Parental Control. Australian Journal of Psychology, 60(2), 63-71.

Goroshko, O., Samoilenko, S. \& Fairfax, D. (2011). Twitter as a Conversation through e-Learning Context. Revista de Informatica Sociala, 23(15), 19.

Hafkin, N. J. (2015). ICTs and Gender Equality: Transformation Through Research?Information Technologies \& International Development, 11(2), 43-45.

Hashim, W. (2015). Electronic Commerce Obstacles for Educated Nigeriai Women. Computer Science and Mobile Computing, 4(2), 24-27.

Hawthorne, S. \& Klein, R. (1999). Cyberfeminism: Connectivity, Critique and Creativity. Spinifex Press.

Heilman, M. E. (2012). Gender Stereotypes and Workplace Bias. Research in Organizational Behavior, 32, $113-135$.

Heinze, N. \& Hu, Q. (2009). Why College Undergraduates Choose IT: A Multi-theoretical Perspective. European Journal of Information Systems, 18(5), 462-475.

Heuwagen, S. E. (2014). A Good Blog Is A Continuing Conversation. How I Learned To Blog And Use Social Media As a Feminist Activist. GEMS, 7(7).

Hillier, L. \& Harrison, L. (2007). Building Realities Less Limited Than Their Own: Young People Practising Same-Sex Attraction on the Internet. Sexualities, 10(1), 82-100.

Princess B. T. Ikyembe (Mrs.). (2011) Information and Communication Technology (Ict): A Catalyst for Women Empowerment in Nigeria. Library and Information Forum Vol 13(1\&2)

Keller, B. \& Mbewe, D. C. (1991). Policy and Planning for the Empowerment of Zambiaes Developement 


\section{2(8), $75-88$.}

Khan, E. A. \& Moin, A. (2013). Women Empowerment : Role of New Media. Excellence International Journal of Education and Research, 1(3), 206-216.

Kothari, C. (2004). Research Methodology: Methods and Techniques. New Age International.

Kvasny, L. (2006). Let the Sisters Speak: Understanding Information Technology from the Standpoint of the “Other.” ACM SIGMIS Database, 37(4), 13.

Kvasny, L., Trauth, E. M. \& Morgan, A. J. (2009). Power Relations in IT Education and Work: The Intersectionality of Gender, Race and Class. Journal of Information, Communication and Ethics in Society, 7, 96-118.

Karolak, M. \& Guta, H. (2015). Veiling and Blogging: Social Media as Sites of Identity Negotiation and Expression among Saudi Women. Journal of International Women's Studies, 16(2), 115-127.

Kimbrough, A. M., Guadagno, R. E., Muscanell, N. L. \& Dill, J. (2013). Gender Differences in Mediated Communication: Women Connect More than Do Men. Computers in Human Behavior, 29(3), 896-900.

Lamont, M. (2013). Gender, Technology, and Libraries. Information Technology and Libraries, 28, $137-142$.

Lehtonen, H. (2014). Social Media and Women of The Arab Spring. University of Jyväskylä.

Lemons, M. \& Parzinger, M. (2007). Gender Schemas: A Cognitive Explanation of Discrimination of Women in Technology. Journal of Business and Psychology, 22, 91-98.

Levy, P. S. \& Lemeshow, S. (2013). Sampling of Populations: Methods and Applications. John Wiley \& Sons.

Lin, K. Y. \& Lu, H. P. (2011). Why People Use Social Networking Sites: An Empirical Study Integrating Network Externalities and Motivation Theory. Computers in Human Behavior, 27(3), 1152-1161.

Livingstone, S. (2008). Taking Risky Opportunities in Youthful Content Creation: Teenagerse Use of Social Networking Sites for Intimacy, Privacy and Self-Expression. New Media \& Society, 10(3), 393-411.89

Malhotra, N. K. (2008). Marketing Research: An applied Orientation. Pearson Education India. Mawaddah, B. M. (2013). Factors Affecting the Success of Nanotechnology Product Commercialisation in Malaysia. UUM.

McCabe, J. (2013). Making Theory Relevant: The Gender Attitude and Belief Inventory. Teaching Sociology, 41, 282-293.

Monami, H. \& Shams, Q. (2014). Empowering Women through Online Bakery Stores in Bangladesh: Barriers and Effective Strategies for Growth and Development. Spearheading ICT4D Knowledge, 4(1), 74.

Moreno, L., González, Y. \& Segura, I. (2014). Women in Computer Science Survey on the Perception of the Women's Participation in STEM Studies. ACM, 11(12), 7-8.

Motter, J. L. (2011). Feminist Virtual World Activism: 16 Days of Activism Against Gender Violence Campaign, Guerrilla Girls BroadBand and subRosa. Visual Culture \& Gender, 6(4), 109-119.

Neuhauser, C. (2007). Project manager leadership behaviors and frequency of use by female project managers. Project Management Quarterly, 38(1), 21.

Newsom, V. A. \& Lara, L. (2012). Arab Women, Social Media, and the Arab Spring: Applying the Framework of Digital Reflexivity to Analyze Gender and Online Activism. Journal of International Women's Studies, 13(5), 31-45.

Njoroge, R. (2013). Impacts of Social Media Among The Youth on Behavior Change: A Case Study of University Students in Selected Universities In Nairobi, Kenya. Universities of Nairobi.

Norusis, M. J. (2011). IBM SPSS Statistics 19 guide to data analysis. Pearson Education. 
Notley, T. M. \& Tacchi, J. a. (2005). Online Youth Networks: Researching the Experiences of "Peripheral" Young People in Using New Media Tools for Creative Participation and Representation. Community, Citizen's and Third Sector Media and Communication, Decision-Making Processes? OECD Development Centre, 2(3), 1-5.

Oliver, K., Collin, P., Burns, J. \& Nicholas, J. (2006). Building Resilience in Young People through Meaningful Participation. Advances in Mental Health, 5(1), 34-40.

Orser, B., Riding, A. \& Stanley, J. (2012). Perceived Career Challenges and Response Strategies of Women in the Advanced Technology Sector. Entrepreneurship \& Regional Development, 24(3), 73-93.

Panko, R. R. (2008). IT Employment Prospects: Beyond the Dotcom Bubble. European Journal of Information Systems, 17(6), 182-197.

Poonia, J., Scholar, T. \& Bhurani, P. (2014). Social Computing: A New Perspective to Enhance the Utilization of Behavioural Modelling. ICSPCT, 402-406.

Raacke, J. \& Bonds-Raacke, J. (2008). MySpace and Facebook: Applying the Uses and Gratifications Theory to Exploring Friend-Networking Sites. CyberPsychology \& Behavior, 11(2), 169-174.

Ramazanoglu, C. \& Holland, J. (2002). Feminist Methodology: Challenges and Choices. SAGE.

Reid, M. F., Allen, M. W., Armstrong, D. J. \& Riemenschneider, C. K. (2010). Perspectives on Challenges Facing Women in IS: The Cognitive Gender Gap. European Journal of Information Systems, 19(5), 526-539.

Richardson, I., Amanda, T. \& MacColl, I. (2007). Moblogging and Belonging : New Mobile Phone Practices and Young Peoplee Sense of Social Inclusion. ACM, 9(4), 73-78.

Rosser, S. V. (2005). Through the Lenses of Feminist Theory: Focus on Women and Information Technology. Frontiers: A Journal of Women Studies, 26(1), 1-23.

Rossi, P. H., Wright, J. D. \& Anderson, A. B. (2013). Handbook of Survey Research. Academic Press.

Rutledge, C. M., Gillmor, K. L. \& Gillen, M. M. (2013). Does This Profile Picture Make Me Look Fat ? Facebook and Body Image in College Students. ResearchGate, 2(4), 251-258.91

Sanda, U.H., Kurfi, M.H (2013). Gendar and Information Technologies in Nigeria: Challenges and Prospectus. Global Journal of Social Science and Sociology and Culture 13(6).Global Journal Inc. (USA)

Sandelowski, M. (2000). Combining Qualitative and Quantitative Sampling, Data Collection, and Analysis Techniques in Mixed-Method Studies. Research in Nursing \& Health, 23(3), 246-255.

Schuler, S. R. \& Rottach, E. (2010). Women"s Empowerment across Generations in Bangladesh.Journal of Development Studies, 46(10), 379-396.

Sekaran, U. \& Bougie, R. (2010). Research Methods for Business: A Skill Building Approach. Wiley London Sekaran, U. \& Bougie, R. (2010). Research Methods for Business: A Skill Building Approach. Wiley London.

Serva, M. A., Baroudi, J. J. \& Kydd, C. T. (2009). The Effects of Stereotype Threat on MIS Students: An Initial Investigation. Journal of Computer Information Systems, 50(2), 51-60.

Shirky, C. (2011). The Political Power of Social Media-Technology,The Public Sphere and Political Change. JSTOR, 90(28), 28-41.

Spiess, J., Joens, Y. T., Dragnea, R. \& Spencer, P. (2014). Using Big Data to Improve Customer Experience and Business Performance. Bell Labs Technical Journal, 18(4), 3-17.

Stavrositu, C. \& Sundar, S. S. (2012). Does Blogging Empower Women? Exploring the Role of Agency and Community. Journal of Computer-Mediated Communication, 17(4), 369-386. 
Stephens, R. J., Metcalf, A., Blanchard, M., Mangan, C. \& Burns, J. (2011). Reaching the Hard-to-Reach: How Information Communication Technologies Can Reach Young People at Greater Risk of Mental Health Difficulties. Australasian Psychiatry, 19(9), 58-61.

Stevens, J. P. (2012). Applied multivariate statistics for the social sciences. Routledge

Stoker, D. J. (1981). Sampling in Practice. University of Pretoria.

Subrahmanyam, K. \& Lin, G. (2007). Adolescents on the Net: Internet Use and Well-Being. Adolescence, 42(168), 659-677.92

Sutton, J. \& Pollock, S. (2000). Online Activism for Women"s Rights. CyberPsychology \& Behavior, 3(5), 699-706.

Tasir, Z., Mohammed, Y., Harun, J. \& Shukor, N. A. (2011). Students ${ }^{\text {ee }}$ Perception towards the Use of Social Networking as an e-Learning Platform. Recent Researches in Education, 5(7), 70-75.

Taussig, M. T. (1980). Reification and The Consciousness of The Patient. Social Science \& Medicine. Part B: Medical Anthropology, 14(1), 3-13.

Timm, D. M. \& Duven, C. J. (2008). Privacy and Social Networking Sites. New Directions for Student Services, 12(124), 89-101.

Trauth, E. M. \& Howcroft, D. (2006). Critical Empirical Research in IS: an Example of Gender and the IT Workforce. Information Technology \& People, 19, 272-292.

Trauth, E. M., Quesenberry, J. L. \& Huang, H. (2006). Cross-Cultural Influences on Women in the IT Workforce. In Proceedings of the 2006 ACM SIGMIS CPR Conference on Computer Personnel Research Forty four years of Computer Personnel Research: Achievements, Challenges \& the Future (pp. 12-19). ACM.

Trauth, E. M., Quesenberry, J. L. \& Huang, H. (2008). A Multicultural Analysis of Factors Influencing Career Choice for Women in the Information Technology Workforce. Journal of Global Information Management, 16(4), 1-23.

Trauth, E. M., Quesenberry, J. L. \& Morgan, A. J. (2004). Understanding The Under representation of Women in IT: Toward a Theory of Individual Differences. In In Proceedings of the 2004 SIGMIS conference on Computer Personnel Research: Careers, Culture, and Ethics in a Networked Environment (pp. 114-119). ACM.

Tufekci, Z. \& County, B. (2008). Grooming, Gossip, Facebook and Myspace. Routledge, 11(4), 544-564.93

UNDP. (2014). Human Development Report 2014. Empowered Lives Resilient Nations, 8(1)

Valkenburg, P. M. \& Peter, J. (2009). Social consequences of the Internet for Adolescents: A decade of Research. Current Directions in Psychological Science, 18(1), 1-5.

Valkenburg, P. M., Peter, J. \& Schouten, A. P. (2006). Friend Networking Sites and Their Relationship to Adolescents"e Well-Being and Social Self-Esteem. CyberPsychology \& Behavior, 9(5), 584-590.

Wagner, D., Vollmar, G. \& Wagner, H.-T. (2014). The Impact of Information Technology on Knowledge Creation: An Affordance Approach to Social Media. Journal of Enterprise Information Management, 27(1), 31-44.

Wajcman, J. (2006). Technocapitalism Meets Technofeminism: Women and Technology in a Wireless World. Labour \& Industry, 16(3), 7-20.

Wentling, R. M. (2009). Workplace Culture that Hinders and Assists the Career Development of Women in Information Technology. Information Technology, Learning, and Performance Journal, 25(1), 25-42. 


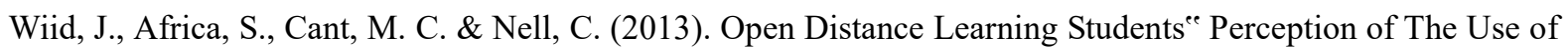
Social Media Networking Systems as an Educational Tool. International Business \& Economics Research Jornal, 12(8), 867-882.

Wilson, J., Lawal, A. K. (2015). The Internet and the Nigerian Woman: A Case of FemaleUndergraduates. KOME - An International Journal of Pure Communication Inquiry. Volume 3 (1) p. 47-65.

Wkh, R. U., \& Ri, G. (2015). A Quantitative Framework of Skill Evaluation of IT Workforce.Business \& Economics Research Jornal, 12(8), 867-882.

Zaidan, A., Zaidan, B., Kadhem, Z., Larbani, M., Lakulu, M. \& Hashim, M. (2015). Challenges, Alternatives, and Paths to Sustainability: Better Public Health Promotion Using Social Networking Pages as Key Tools. Springer, 39(7), 1-14.

Zikmund, W. G., Carr, J. C., Griffi, M. \& Jacobsen, B. (2010). Business Research Methods. South-Western, Cengage Learning, 8, 1-18.

Zita, M., Burger, C. \& Scholtz, B. (2014). The Use of Social Media as an Enabler to Create Environmental Awareness of Staff in Higher Education. In Proceedings of the 28th EnviroInfo 2014 Conference (pp. 25-32).

\section{Copyrights}

Copyright for this article is retained by the author(s), with first publication rights granted to the journal.

This is an open-access article distributed under the terms and conditions of the Creative Commons Attribution license (http://creativecommons.org/licenses/by/4.0/). 